\title{
A Case of Multiple Cutaneous Granulocytic Sarcomas in an Elderly Patient
}

\author{
Nursel Dilek ${ }^{\mathrm{a}, \mathrm{d}}$, Aziz Ramazan Dilek ${ }^{\mathrm{b}}$, Yunus Saral ${ }^{\mathrm{a}}$, Recep Bedir ${ }^{\mathrm{c}}$
}

\begin{abstract}
Granulocytic sarcoma (GS) is an extramedullary tumor composed of malignant myeloid precursor cells. GS commonly presents in soft tissues of head, neck and in intracranial sites, but GS may arise anywhere in the body. The diagnosis is made clinically on the basis of a combination of location, pathologic appearance, and a concurrent diagnosis of acute leukemia or myelodysplastic syndrome (MDS). GS is generally presenting as a single lesion. We present an elderly patient with multiple cutaneous GS who has acute myelogenous leukemia (AML). Since GS often precedes leukemia, early recognition and a definitive diagnosis of GS is very important for proper and timely treatment.
\end{abstract}

Keywords: Granulocytic sarcoma; Leukemia; Myelodysplastic syndrome

\section{Introduction}

Granulocytic sarcoma (GS) is an extramedullary tumor composed of malignant myeloid precursor cells, first described by Burns in 1811; in 1853 King coined the term "chloroma", due to the presence of myeloperoxidase [1]. The preferred term "granulocytic sarcoma" was named by Rappaport in 1966 and has been widely adopted since [2]. GS commonly presents in soft tissues of head, neck and in intracranial sites, but GS may arise anywhere in the body. The diagnosis is made clinically on the basis of a combination of location, pathologic appearance, and a concurrent diagnosis of acute leukemia or myelodysplastic syndrome (MDS) [3]. The lesion generally occurs

\footnotetext{
Manuscript accepted for publication July 18, 2014

aDermatology Department of Recep Tayyip Erdogan University Medical Faculty Hospital, Rize, Turkey

bMicrobiology Department of Recep Tayyip Erdogan University, Medical Faculty Hospital, Rize, Turkey

${ }^{\mathrm{c}}$ Pathology Department of Recep Tayyip Erdogan University, Medical Faculty Hospital, Rize, Turkey

${ }^{\mathrm{d} C}$ Corresponding Author: Nursel Dilek, Dermatology Department, Rize Education and Research Hospital, Rize, Turkey. Email: nur.dilek@hotmail.com
}

doi: http://dx.doi.org/10.14740/jmc1410w either during the natural course of acute myelogenous leukemia (AML) or after a remission has been achieved; however, it may rarely represent the initial manifestations of the disease [4]. While GS is reported in $0.7-9 \%$ of patients with AML or chronic myelogenous leukemia [5], extramedullary leukemia involving the skin has been described in approximately $2-3 \%$ of AML cases [6]. Cutaneous lesions usually occur on the trunk, scalp and extremities [7]. GS occurs more commonly in children and young adults [2].

GS is generally presenting as a single lesion, less frequently multiple lesions as in our case [1]. We present an elderly patient with multiple cutaneous GS who has AML.

\section{Case Report}

A 72-year-old male patient, who has MDS for 7 years consulted due to papules and nodules on his trunk, head and the root of the extremities by our dermatology clinic. The patient was not receiving any treatment for last 2 years due to the disease in remission. He had no complaint of pain and itching due to the lesions and other systemic symptoms. In physical examination, multiple red-brown papules and nodules measuring 0.5-2 $\mathrm{cm}$ in diameter on trunk, head and the root of the extremities were seen (Fig. 1a, b). There was no organomegaly, lymphadenopathy, clinical signs of infection. In hematological investigation, white blood cell count was $7.36 \times 10^{9} / \mathrm{L}$, hemoglobin was $10.4 \mathrm{~g} / \mathrm{dL}$, platelet count was $130 \times 10^{9} / \mathrm{L}$, and red blood cell count was $2.97 \times 10^{12} / \mathrm{L}$. Other routine biochemical tests and urinalysis were normal. Computed tomography of the thorax and the abdomen showed no abnormalities. A skin biopsy was performed and showed a dense cellular infiltrate in dermis (Fig. 2). The cells were large with oval nuclei, fine chromatin and small nucleoli. Immunohistochemical studies were positive for CD43, CD117 and myeloperoxidase. Hypercellularity, myeloperoxidase, leukocyte specific antigen positivity and increasing of blasts cell were seen in bone marrow aspiration. Based on these findings, the patient was diagnosed as AML. The patient did not accept further treatment.

\section{Discussion}

MDS incorporates a heterogeneous group of clonal stem cell 

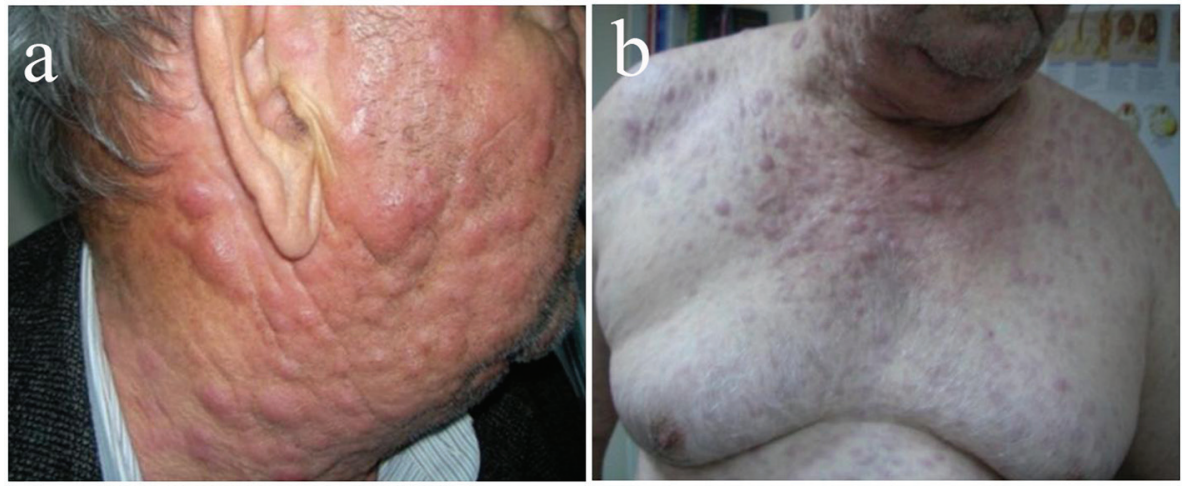

Figure 1. Multiple red-brown papules and nodules on (a) neck and face and (b) trunk.

disorders characterized by peripheral blood cytopenia(s) due to ineffective hematopoiesis and dysplasia in one or more of the myeloid lineages. MDS is the most common hematological malignancy, with an overall incidence of $3-5 / 100,000$ individuals per year $[8,9]$. A high incidence of progression to AML and/or marrow failure has been also reported in patients with MDS $[8,10]$. The occurrence of cutaneous GS in the context of MDS is rare and often a sign of poor prognosis [7]. GS is an extramedullary solid tumor mass composed of immature myeloid cells. GS is a rare manifestation of AML usually arising during or after the course of the disease, in up to $8 \%$ of patients in autopsy studies. Sometimes, GS can be the first and the only manifestation of AML, leading to diagnostic challenges as in our case [11]. The clinical aspect and histological picture of cutaneous GS can easily be mistaken for a cutaneous lymphoma, therefore immunohistochemical assessment is mandatory for correct diagnosis, because it reveals the myeloid lineage of the cells (myeloperoxidase, CD68, chloroacetate esterase, lysozyme, CD43, CD31, CD34, CD38, CD45, CD99, CD117, CD79a, and CD3) $[1,3,11]$. In immunohistochemical studies for confirming the diagnosis, CD43, CD117, and myeloperoxidase were positive in our case. Therapeutic options for GS are chemotherapy, radiation and surgery. Radiation therapy is palliative and suited for patients with localized or diffused disease

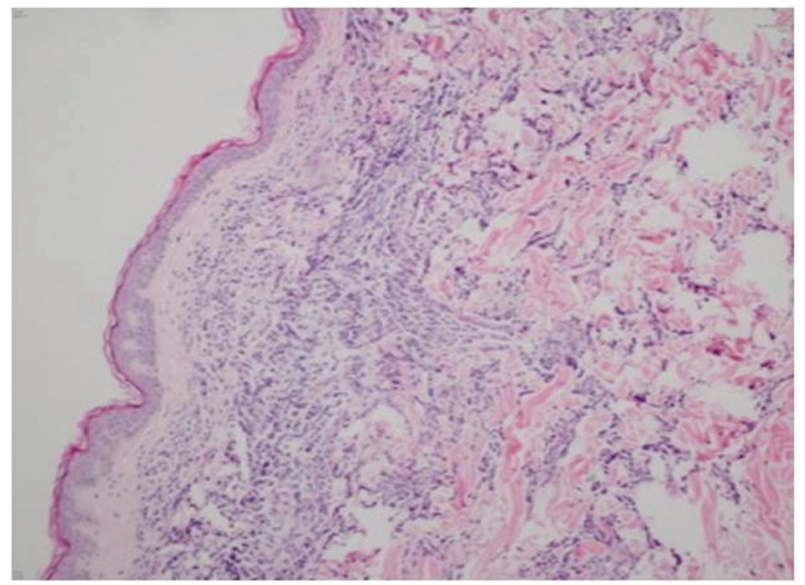

Figure 2. Dense cellular infiltrate in dermis. and most GS respond to external beam radiation. Surgery is limited to situations where there is tumor compression [2]. The role of systemic chemotherapy is well established in leukemic patients. In patients without concurrent leukemia, aggressive combination chemotherapy prolongs life and may prevent the onset of leukemia [7]. In our case, the patient did not accept further treatment, therefore treatment planning could not be made.

In conclusion, considering that GS is a rare manifestation of AML and sometimes GS can be the first and the only manifestation of AML, careful clinical correlation led to the proper diagnosis in our case. Since GS often precedes leukemia, early recognition and a definitive diagnosis of GS is very important for proper and timely treatment.

\section{Conflict of Interest}

Authors declare no conflict of interest.

\section{References}

1. Pulsoni A, Falcucci P, Anghel G, Ribersani M, Petrucci MT, Pescarmona E, Muscardin L. Isolated granulocytic sarcoma of the skin in an elderly patient: good response to treatment with local radiotherapy and low-dose methotrexate. J Eur Acad Dermatol Venereol. 2000;14(3):216218.

2. Cheah KL, Lim LC, Teong HH, Chua SH. A case of generalised cutaneous granulocytic sarcoma in an elderly patient with myelodysplastic syndrome. Singapore Med J. 2002;43(10):527-529.

3. Gorman M, Ahmed KA, Pallera A, Samant S. Granulocytic sarcoma of the nasal cavity: a case report. Ear Nose Throat J. 2009;88(11):1210-1212.

4. D'Costa GF, Hastak MS, Patil YV. Granulocytic sarcoma of breast: an aleukemic presentation. Indian J Med Sci. 2007;61(3):152-155.

5. Chargari C, Jacob J, Bauduceau O, Ferrand FR, De Revel T, Vedrine L. Granulocytic sarcoma in a nonleukemic patient: place of radiotherapy and systemic therapies. Case 
Rep Med. 2011;2011:929161.

6. Amador-Ortiz C, Hurley MY, Ghahramani GK, Frisch S, Klco JM, Lind AC, Nguyen TT, et al. Use of classic and novel immunohistochemical markers in the diagnosis of cutaneous myeloid sarcoma. J Cutan Pathol. 2011;38(12):945-953.

7. de Arruda Camara VM, Morais JC, Portugal R, da Silva Carneiro SC, Ramos-e-Silva M. Cutaneous granulocytic sarcoma in myelodysplastic syndrome. J Cutan Pathol. 2008;35(9):876-879.

8. Suzanne MV, Aly K. Myelodysplastic Syndromes: Evolving Insights. Canadian Journal of Pathology.
2011;3(4):31-37.

9. Kawankar N, Vundinti BR. Cytogenetic abnormalities in myelodysplastic syndrome: an overview. Hematology. 2011;16(3):131-138.

10. Murakami Y, Nagae S, Matsuishi E, Irie K, Furue M. A case of $\mathrm{CD} 56+$ cutaneous aleukaemic granulocytic sarcoma with myelodysplastic syndrome. Br J Dermatol. 2000;143(3):587-590.

11. Messager M, Amielh D, Chevallier C, Mariette C. Isolated granulocytic sarcoma of the pancreas: a tricky diagnostic for primary pancreatic extramedullary acute myeloid leukemia. World J Surg Oncol. 2012;10:13. 